\title{
Base-free Enantioselective C(1)-Ammonium Enolate Catalysis Exploiting Aryloxides: A Synthetic and Mechanistic Study
}

\author{
Calum McLaughlin, Alexandra M. Z. Slawin and Andrew D. Smith*
}

Dedication ((optional))

\begin{abstract}
An isothiourea-catalyzed enantioselective Michael addition of aryl ester pronucleophiles to vinyl bis-sulfones via $\mathrm{C}(1)$ ammonium enolate intermediates has been developed. This operationally simple method allows the base-free functionalization of aryl esters to form a-functionalized products containing two contiguous tertiary stereogenic centres in excellent yield and stereoselectivity (all $\geq 99: 1 \mathrm{er}$ ). Key to the success of this methodology is the multifunctional role of the aryloxide, which operates as a leaving group, Brønsted base, Brønsted acid and Lewis base within the catalytic cycle. Comprehensive mechanistic studies, including variable-time normalization analysis (VTNA) and isotopologue competition experiments, have been carried out. These studies have identified (i) orders of all reactants; (ii) a turnoverlimiting Michael addition step, (iii) product inhibition, (iv) the catalyst resting state and $(\mathrm{v})$ catalyst deactivation through protonation.
\end{abstract}

\section{Introduction}

$\mathrm{C}(1)$-Ammonium enolates ${ }^{[1]}$ have emerged as powerful catalytically-generated synthetic intermediates for enantioselective C-C and C-X bond formation. Traditionally generated from Lewis basic tertiary amine catalysts $^{[2]}$ and ketenes, ${ }^{[3]}$ recent advances have sought to access $C(1)$ ammonium enolates directly from either carboxylic acids ${ }^{[1 \mathrm{~b}, 4]}$ or activated aryl esters. ${ }^{[5]}$ When using carboxylic acid starting materials, the most common approach involves in situ derivatization to an anhydride prior to preparation of the $\mathrm{C}(1)$ ammonium enolate. Although powerful in concept, this strategy is limited in terms of sustainability and atom economy. As exemplified in Scheme 1, treatment of phenylacetic acid with excess activating agent (such as $t$ - $\mathrm{BuCOCl}, 1.5$ equiv.) is necessary to generate a reactive anhydride in situ prior to $\mathrm{C}(1)$ ammonium enolate formation, while excess auxiliary base (such as $i-\mathrm{Pr}_{2} \mathrm{NEt}, 4.0$ equiv.) is required for effective catalysis. ${ }^{[6]}$ These methodologies generally require the use of an electrophile that contains a latent nucleophilic site (such as an enone), in order for catalyst turnover to be achieved through intramolecular cyclization to give formal cycloaddition products (Scheme 1, inset).

Building upon Lectka's pioneering work using halogenated quinones as electrophiles for the in situ generation of aryloxides, ${ }^{[7]}$ recent work has focused on using electron-deficient aryl esters as $\mathrm{C}(1)$-ammonium enolate precursors in isothiourea

[a] Mr C. McLaughlin, Prof. A. M. Z. Slawin, Prof. A. D. Smith EaStCHEM, School of Chemistry, University of St Andrews, North Haugh, Fife, Scotland, UK. KY16 9ST

E-mail: ads10@st-andrews.ac.uk

Supporting information for this article is given via a link at the end of the document.
Previous work: Enantioselective Michael addition-lactonization

$$
\text { x electrophile requires latent nucleophile for catalyst turnover via I }
$$

Scheme 1. Intramolecular catalyst turnover in ammonium enolate catalysis.

catalysis. ${ }^{[8]}$ In our previous work this strategy was first applied to the enantioselective [2,3]-rearrangement of allylic ammonium ylides to form stereodefined $\alpha$-amino acid derivatives (Scheme $2 a){ }^{[9]}$ In this case, aryloxide released upon addition of the Lewis base catalyst to a para-nitrophenyl ester substrate was used to attack the post-rearrangement acyl ammonium intermediate II (or its HOBt ester equivalent) and regenerate the free catalyst. ${ }^{[10]}$ Building upon this approach, Snaddon and co-workers have developed elegant $\alpha$-allylation and $\alpha$-benzylation protocols of pentafluorophenyl esters in union with palladium catalysis (Scheme $2 \mathrm{~b}){ }^{[11]}$ while Hartwig and co-workers developed a cooperative isothiourea/iridium-catalyzed allylation. ${ }^{[12]}$ In previous work we reported the enantioselective addition of $\mathrm{C}(1)$ ammonium enolates, generated from para-nitrophenyl esters, to iminium ion electrophiles, however stoichiometric tetra- $n$-butyl ammonium para-nitrophenoxide was also required as an

Recent advances: aryloxide promoted "intermolecular" catalyst turnove (a) Enantioselective [2,3]-rearrangement of allylic ammonium ylides

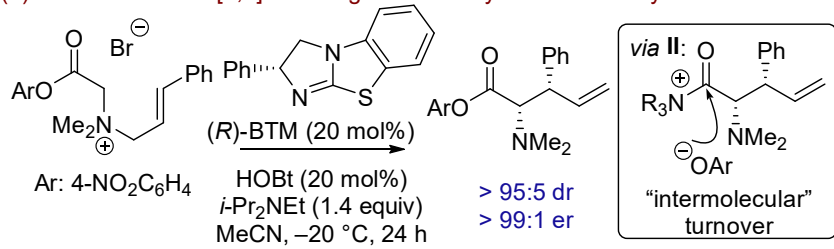

(b) Enantioselective Pd-catalyzed allylation/benzylation

$$
\mathrm{Ar}=\mathrm{C}_{6} \mathrm{~F}_{5}
$$<smiles>COC(=O)C(Cc1ccccc1)c1ccccc1</smiles>

(c) Enantioselective addition to iminium ions

99:1 er

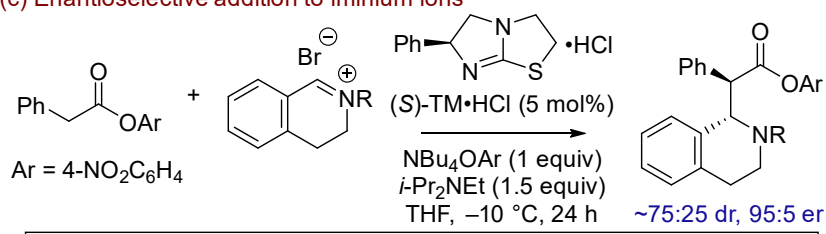

$\checkmark$ aryloxide promoted catalyst turnover broadens reaction scope X high catalyst loadings common $(20 \mathrm{~mol} \%) \times$ no mechanistic analysis $\mathbf{x}$ stoichiometric auxiliary base or additive required for optimal reactivity

Scheme 2. Aryloxide promoted intermolecular catalyst turnover in enantioselective ammonium enolate catalysis. (HOBt: hydroxybenzotriazole). 
additive for optimal reactivity (Scheme 2c). ${ }^{[13]}$ While these impressive strategies broaden the compatibility of $\mathrm{C}(1)$ ammonium enolate intermediates in dual catalytic processes and with alternative electrophilic components, all typically employ high catalyst loadings of the Lewis base (commonly 20 $\mathrm{mol} \%$ ) as well as excess auxiliary base. Furthermore, these latter processes (Scheme 2b,c) are not well-understood mechanistically in terms of identification of reaction intermediates, reaction orders with respect to components, and turnover-limiting step.

Given this background, we envisaged an alternative basefree and proton neutral Lewis base-catalyzed strategy for the catalytic enantioselective functionalization of electron-deficient aryl esters. Addition of an isothiourea Lewis base to an aryl ester would initially generate an acyl ammonium aryloxide ion pair, with deprotonation of the acyl ammonium by the aryloxide generating the reactive $\mathrm{C}(1)$-ammonium enolate. Enantioselective Michael addition to a suitable acceptor, followed by proton transfer from the in situ generated phenol, and subsequent aryloxide turnover would deliver $\alpha$-alkylated products containing two tertiary stereogenic centres (Scheme 3 ). This approach would circumvent the previous necessity for the addition of an auxiliary base but would require the aryloxide to fulfill the role of proton shuttle within the catalytic cycle. In this manuscript, this concept is demonstrated through the isothiourea-catalyzed Michael addition of ester pronucleophiles to bis-sulfone Michael acceptors, where the sulfone groups present within the reaction product provide functional handles for further derivatization. Mechanistic investigations have been carried out to analyze the temporal concentrations of the reaction components, with variable time normalization analysis (VTNA) used to determine their respective orders. Catalyst deactivation and product inhibition effects were also found to be significant over the reaction course. Measurement of a kinetic isotope effect $(\mathrm{KIE})$ was used to identify the turnover-limiting step of the catalytic process.

This work: base-free functionalization of esters

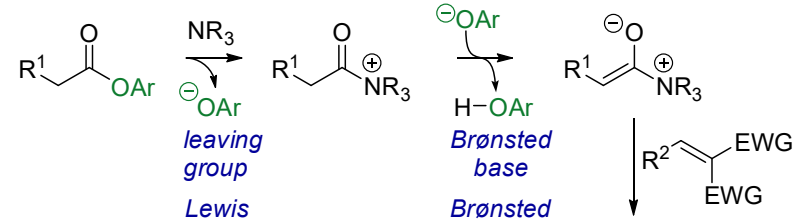

$$
\begin{aligned}
& \text { (1) }
\end{aligned}
$$

Scheme 3 This work: base-free enantioselective ammonium enolate catalysis. (EWG: electron-withdrawing group).

\section{Results and Discussion}

\section{Optimization Studies}

Proof-of-principle studies commenced using para-nitrophenyl ester 1, 1.1 equivalents of vinyl bis-sulfone $\mathbf{2}$ and tetramisole $\cdot \mathrm{HCl} 3(20 \mathrm{~mol} \%)$ in dichloromethane at room temperature for 24 hours (Table 1, entry 1 ). Whilst the product ester could be isolated following chromatographic purification, it proved unstable to HPLC analysis and so all further products were isolated as the corresponding benzyl amide following addition of benzylamine at the end of the reaction. Encouragingly, amide 4 was formed in good yield (67\%) with high diastereoselectivity $(88: 12 \mathrm{dr})$ and excellent enantioselectivity (> 99:1 er). The use of various isothiourea catalysts was next investigated. Benzotetramisole (BTM) 5 gave the product in improved yield $(78 \%$, entry 2$)$, whilst maintaining high $\mathrm{dr}(86: 14)$ and er (> 99:1). Using HyperBTM 6 as catalyst gave amide 4 in a lower yield of $60 \%$ yield, although excellent stereoselectivity was still observed (entry 3 ). Notably, consistent with our mechanistic hypothesis (Scheme 3 ), the use of an external base was not necessary for effective catalysis. The catalyst loading of BTM 5 could be reduced to 5 mol\% whilst maintaining high diastereo- and enantioselectivity, however 4 was obtained in lower yield $(54 \%$, entry 4$)$. Reversing the stoichiometry and increasing the ester equivalents (1.5 equiv.) and concentration $(0.5 \mathrm{M})$ provided amide 4 in improved yield (entry 5 ). The use of alternative, industrially preferable solvents (dimethylcarbonate, iso-propyl acetate) ${ }^{[14]}$ provided amide 4 in comparable yields and stereoselectivity with the exception of 2methyl THF which led to reduced yields and $\mathrm{dr}$ (entries 6-8).

Table 1. Reaction optimization.

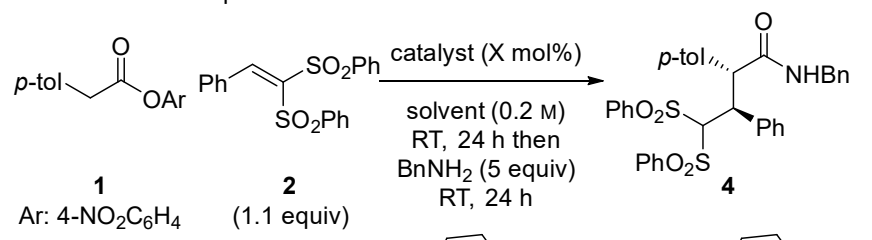

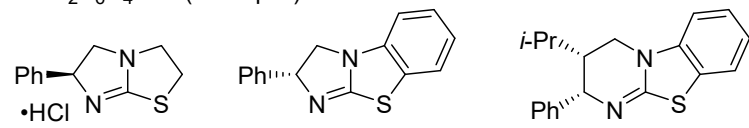

$(\mathrm{S})-\mathrm{TM} \cdot \mathrm{HCl}(\mathbf{3}) \quad(R)-\mathrm{BTM}(5)$

$(2 S, 3 R)$-HyperBTM (6)

\begin{tabular}{cccccc}
\hline Entry & Catalyst (mol\%) & Solvent & $\begin{array}{c}\text { Yield }^{a} \\
(\%)\end{array}$ & $\mathrm{dr}^{b}$ & $\mathrm{er}^{c}$ \\
\hline $1^{d}$ & $(\mathrm{~S})$-TM·HCl (20) & $\mathrm{CH}_{2} \mathrm{Cl}_{2}$ & 67 & $88: 12$ & $<1: 99$ \\
2 & $(R)$-BTM (20) & $\mathrm{CH}_{2} \mathrm{Cl}_{2}$ & 78 & $86: 14$ & $>99: 1$ \\
3 & $\begin{array}{c}(2 S, 3 R) \text {-HyperBTM } \\
(20)\end{array}$ & $\mathrm{CH}_{2} \mathrm{Cl}_{2}$ & 60 & $80: 20$ & $98: 2$ \\
4 & $(R)$-BTM (5) & $\mathrm{CH}_{2} \mathrm{Cl}_{2}$ & 54 & $89: 11$ & $>99: 1$ \\
$5^{e}$ & $(R)$-BTM (5) & $\mathrm{CH}_{2} \mathrm{Cl}_{2}$ & $\mathbf{8 6}(75)$ & $89: 11$ & $>99: 1$ \\
$6^{e}$ & $(R)$-BTM (5) & DMC & 85 & $89: 11$ & $98: 2$ \\
$7^{e}$ & $(R)$-BTM (5) & i-PrOAc & 89 & $89: 11$ & $>99: 1$ \\
$8^{e}$ & $(R)$-BTM (5) & 2-MeTHF & 63 & $79: 21$ & $>99: 1$ \\
\hline
\end{tabular}

[a] Combined yield of major and minor diastereomers. Determined by ${ }^{1} \mathrm{H}$ NMR analysis of the crude reaction mixture using 1,3,5-trimethoxybenzene internal standard. Isolated yield of major diastereoisomer in parenthesis. [b] Determined by ${ }^{1} \mathrm{H}$ NMR analysis of the crude reaction mixture. [c] Determined by chiral HPLC analysis. [d] 1.0 equiv. $i$ - $\mathrm{Pr}_{2} \mathrm{NEt}$ added. [e] 1.5 equiv. $1,1.0$ equiv. 2, $0.5 \mathrm{M}$ concentration. (DMC: dimethylcarbonate). 
Key to this strategy is the multiple roles of the aryloxide within the catalytic cycle. It is required to be an effective leaving group for $\mathrm{N}$-acylation, to act as a Brønsted base and a Brønsted acid (as the corresponding phenol), before acting as a Lewis base. The steric and electronic effects of the aryloxide leaving group were examined to gain insight into the subtle effects that could alter its nucleophilicity, nucleofugality and basicity (Table 2). ${ }^{15}$ Using para-nitrophenyl ester 7 allowed ester 13 to be isolated in high yield, dr and er (entry 1, 84\%, 84:16 dr, > 99:1 er). Reaction of pentafluorophenyl ester 8 gave product 14 in lower yield (39\%), although excellent stereocontrol was maintained (entry 2). The use of tetrafluorophenyl ester 9 gave product 15 in $56 \%$ yield (entry 3 ), whilst 3,5-bis(trifluoromethyl) ester 10 gave product 16 in $44 \%$ yield (entry 4 ). Interestingly, the reaction of both 2,4,6-trichlorophenyl ester 11 and the parent phenyl ester 12 showed no reactivity (entries 5 and 6). Correlation of the observed reactivity with variation in $\mathrm{pK} K_{\mathrm{a}}$ of the phenol can be identified. para-Nitrophenol (pKa 7.1 in $\left.\mathrm{H}_{2} \mathrm{O}\right)^{[16]}$ is an efficient leaving group but is capable of the desired amphoteric behavior and promoting catalyst turnover. Pentafluorophenol ( $p K a$ 5.53) and tetrafluorophenol ( $p K a$ 6.0) have lower $p K a$ values, ${ }^{[17]}$ with the corresponding aryloxides less Brønsted basic and less nucleophilic, presumably resulting in lower concentrations of the reactive ammonium enolate. Despite 2,4,6-trichlorophenol having a comparable pKa (5.99) to tetrafluorophenol, the lack of reactivity is presumably due to the steric demands of the ortho-substituents attenuating its nucleophilicity. ${ }^{[18]}$ The ester derived from phenol is less electrophilic and does not acylate the catalyst. A careful balance of leaving group ability, amphoteric behaviour and steric effects within this series indicates that para-nitrophenol is the most effective aryloxide for this application.

Table 2. Aryloxide study.

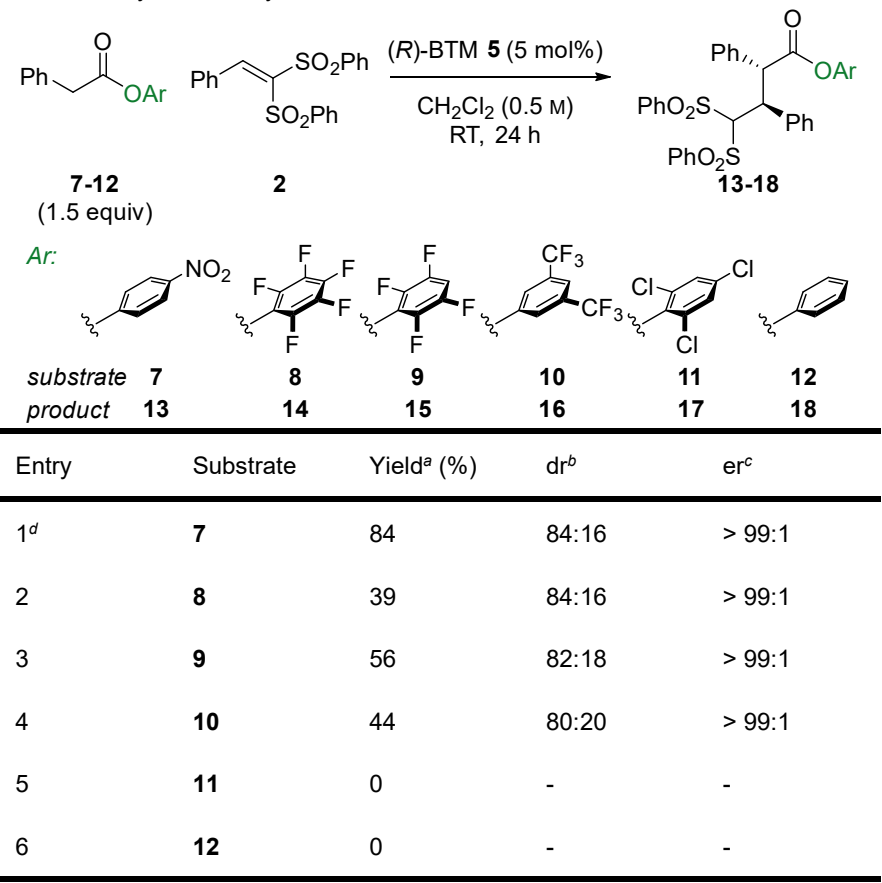

[a] Isolated yield of major diastereoisomer. [b] Determined by ${ }^{1} \mathrm{H}$ NMR analysis of the crude reaction mixture. [c] Determined by chiral HPLC analysis after conversion to the corresponding benzyl amide. [d] isolated as 95:5 dr.

\section{Scope and Limitations}

The generality of the Michael addition protocol was next investigated by exploring the scope of the ester component (Table 3). Dichloromethane proved the most general solvent for effective catalysis upon extension to alternative substrates (see SI for further details). ${ }^{[19]}$ The diastereoisomers were separable by column chromatography and the quoted yield in Table 3 refers to the isolated yield of the major diastereoisomer. Firstly, a range of substituted arylacetic para-nitrophenyl esters with different steric and electronic properties was explored. Electronneutral phenyl, 4-biphenyl and 2-naphthyl groups provided the corresponding amide products $\mathbf{3 8}, \mathbf{3 9}$ and $\mathbf{4 0}$ in high yield and diastereoselectivity, with exceptional enantiocontrol (all $\geq 99: 1$ er). Electron-donating aryl substituents (such as 4-tolyl, 4methoxyphenyl and 4-dimethylaminophenyl) gave the corresponding amide products 4, 41-44 in good yield and with high diastereoselectivity ( $~ 90: 10 \mathrm{dr})$. The relative and absolute configuration of the major $(2 R, 3 S)$-diastereoisomer 4 was determined by single crystal $\mathrm{X}$-ray crystallography with all other products assigned by analogy. ${ }^{[20]}$ Halogen-substituted aryl rings gave amides 45-47 in good yield and er, although in reduced dr ( 80:20 dr). Introduction of the electron-withdrawing 4trifluoromethylphenyl group gave product 48 in diminished diastereoselectivity $(76: 24 \mathrm{dr})$, albeit still in high yield and enantiopurity for both diastereoisomers. Epimerization studies were undertaken to probe the low diastereoselectivity (see SI); no product epimerization under the reaction conditions was observed, indicating the diastereoselectivity is derived from the orientation of the electrophile on approach. ${ }^{[21]}$ Having demonstrated a range of substituted aryl rings were compatible with the optimized conditions, attention was turned to other classes of ester. Pleasingly, alkenyl substituents were tolerated, with amide 49 obtained in $66 \%$ yield and with good stereoselectivity. Heteroaryl esters were also compatible, with 2thiophenyl amide $\mathbf{5 0}$ obtained in high yield and dr; both diastereoisomers were obtained in $>99: 1 \mathrm{er}$. The relative and absolute configuration within the minor $(2 R, 3 R)$-diastereoisomer 50 was also determined by single crystal X-ray crystallography. ${ }^{[22]}$ This is consistent with high enantiocontrol at $\mathrm{C}(2)$ for both diastereoisomers, which are epimeric at $\mathrm{C}(3)$. Unfortunately, alkyl, a, a-disubstituted and benzyloxy esters were unreactive in this protocol, only returning starting materials, ${ }^{[23]}$ whilst ortho-substitution gave product in diminished yield and lower diastereoselectivity (see $\mathrm{SI}$ ).

The scope of the developed process was further tested by variation of the electrophile component (Table 3). Firstly, the effect of the $\beta$-substituent was examined: the use of an electrophile bearing a 4-fluorophenyl substituent gave amide $\mathbf{5 1}$ in excellent yield, $d r$ and er. However, substitution with an electron-donating 4-methoxyphenyl gave amide $\mathbf{5 2}$ in lower yield. Using the commercially available unsubstituted bis(phenylsulfonyl)ethylene electrophile provided a single enantiomer of amide $\mathbf{5 3}$ in high yield (78\%). The scope of the electrophile was extended to alkyl sulfone groups, with methyl sulfone giving amide $\mathbf{5 4}$ in acceptable yield (55\%). The use of a cyclic bis-sulfone allowed access to amide $\mathbf{5 5}$ in excellent yield, $\mathrm{dr}$ and er but required acetonitrile as the reaction solvent due to 
Table 3. Reaction scope

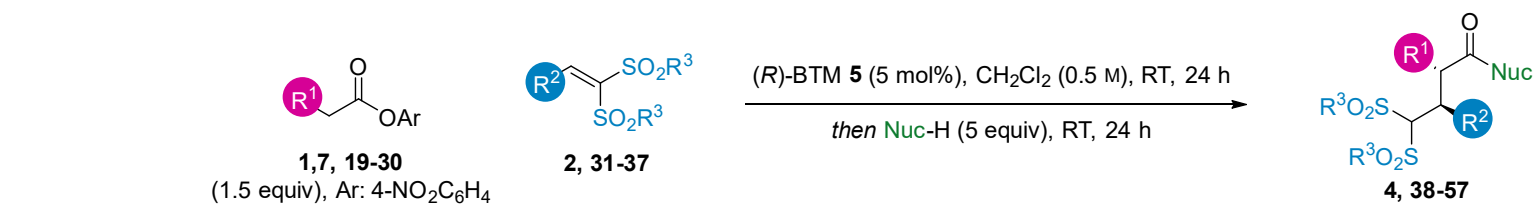<smiles>O=C(NCc1ccccc1)[C@H](c1ccccc1)[C@@H](c1ccccc1)C([PbH])OP</smiles>

38; $80 \%$

$88: 12 \mathrm{dr} ;>99: 1$ er<smiles>COc1ccc([C@H](C(=O)NCc2ccccc2)C(c2ccccc2)C(Oc2ccccc2)c2ccccc2)cc1</smiles>

42; $61 \%$

$88: 12$ dr; > 99:1 er<smiles>O=C(NBr)[C@H](c1ccc(C(F)(F)F)cc1)[C@H](c1ccccc1)C(S(=O)(=O)O)[SH](=O)(O)O</smiles>

48; $76 \%^{b}$

$76: 24 \mathrm{dr}$ 99:1 er $_{\text {maj; }} ; 99: 1$ er $_{\text {min }}$

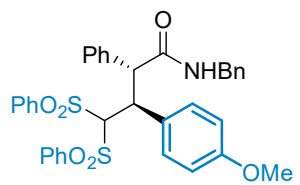

52; $27 \%$

86:14 dr; > 99:1 er

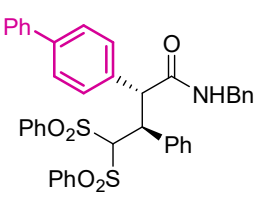

39; $81 \%$ 81:19 dr; 99:1 er<smiles>COc1ccc([C@H](C(=O)NCc2ccccc2)[C@H](c2ccccc2)C(S(=O)(=O)c2ccccc2)S(=O)(=O)c2ccccc2)cc1OC</smiles>

43; $72 \%$ 90:10 dr; > 99:1 er<smiles>C/C=C/[C@H](C(=O)NCc1ccccc1)C(c1ccccc1)C(c1ccccc1)[Sb](=O)(O)O</smiles>

49; $66 \%$ 80:20 dr; > 99:1 er<smiles>O=C(NCc1ccccc1)C(CC(SO)P(O)c1ccccc1)c1ccccc1</smiles>

53; $78 \%$ $>99: 1$ er<smiles>O=C(NCc1ccccc1)[C@H](c1ccc2ccccc2c1)C(c1ccccc1)C(S(=O)(=O)O)S(=O)(=O)c1ccccc1</smiles>

40; $83 \%$ $88: 12 \mathrm{dr} ;>99: 1$ er<smiles>CN(C)c1ccc([C@H](C(=O)NCc2ccccc2)[C@H](c2ccccc2)C(c2ccccc2)S(=O)(=O)Oc2ccccc2)cc1</smiles>

44; $57 \%$ 89:11 dr; > 99:1 er<smiles>O=C(NCc1ccccc1)[C@H](c1ccsc1)[C@H](c1ccccc1)C(S(=O)(=O)Oc1ccccc1)[SH](=O)(O)c1ccccc1</smiles>

(2R,3S)-50 $\mathbf{0}_{\text {maj }}$ $78 \%{ }^{c} 88: 12 \mathrm{~d}$<smiles>Cc1ccc([C@H](C(=O)NCc2ccccc2)[C@H](c2ccccc2)C([C@@H](C(=O)NCc2ccccc2)c2ccccc2)S(=O)(=O)Oc2ccccc2)cc1</smiles>

4; $75 \%$ $90: 10 \mathrm{dr} ;>99: 1$ er

$(2 R, 3 S)-\mathbf{4}_{\text {maj }}$<smiles>O=C(NCc1ccccc1)[C@H](c1ccc(F)cc1)[C@H](c1ccccc1)C(S(=O)(=O)Oc1ccccc1)[SH](=O)(O)c1ccccc1</smiles>

45; $58 \%$ 85:15 dr; > 99:1 er<smiles>O=C(NCc1ccccc1)[C@H](c1ccc(Cl)cc1)C(c1ccccc1)C(Sc1ccccc1)S(=O)(=O)O</smiles>

46; $78 \%$ $80: 20 \mathrm{dr} ;>99: 1$ er<smiles>Cc1cccc([C@H](C(=O)NCc2ccccc2)C(c2ccccc2)C(c2ccccc2)S(=O)(=O)Oc2ccccc2)c1</smiles>

41; $57 \%$ $85: 15 \mathrm{dr} ;>99: 1$ er

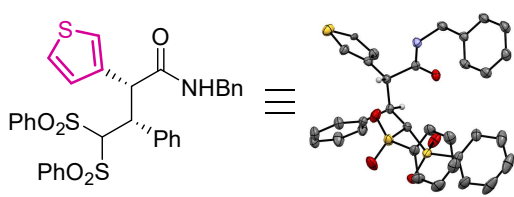

$(2 R, 3 R)-50_{\text {min }}$<smiles>O=C(NCc1ccccc1)[C@H](c1ccc(Br)cc1)C(c1ccccc1)C(Sc1ccccc1)S(=O)(=O)Oc1ccccc1</smiles>

47; $68 \%$ $82: 18 \mathrm{dr} ;>99: 1$ er
$51,80 \%$ $88: 12 \mathrm{dr} ;>99: 1 \mathrm{er}$ $>99: 1 \mathrm{er}_{\text {maj }}$; $>99: 1 \mathrm{er}_{\text {min }}$<smiles>COC(OC)C(c1ccccc1)[C@@H](C(=O)NCc1ccccc1)c1ccccc1</smiles>

\section{$54 ; 55 \%^{e}$}

$80: 20 \mathrm{dr}$ 99:1 er $_{\text {maj }}$; > 99:1 er $r_{\text {min }}$<smiles>O=C(NCc1ccccc1)[C@H](c1ccccc1)[C@H](c1ccccc1)C1SCCC[Se]1=O</smiles>

$55 ;^{f} 84 \%$ $84: 16 \mathrm{dr}$ 99:1 er

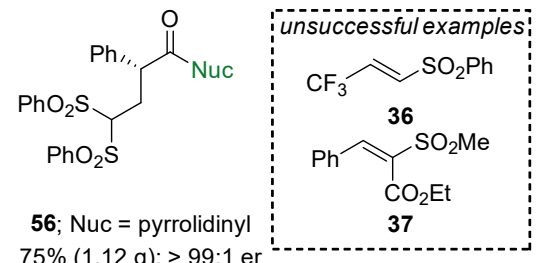

$75 \%(1.12 \mathrm{~g}) ;>99: 1 \mathrm{er}$

57; $\mathrm{Nuc}=\mathrm{OMe}$

$82 \% ; 99: 1 \mathrm{er}^{d}$

[a] dr determined by ${ }^{1} \mathrm{H}$ NMR analysis of the crude reaction mixture; isolated yield of a single major diastereoisomer; er determined by chiral HPLC analysis. [b] isolated > 95:5 dr. [c] combined yield of separable diastereoisomers. [d] er determined after reduction to corresponding alcohol (58). [e] isolated 80:20 dr. [f] $\mathrm{MeCN}$ as solvent.

the insolubility of the electrophile in dichloromethane. Unfortunately, Michael acceptors bearing a single sulfone group (36, 37) were unreactive, presumably due to the lower electrophilicity of these acceptors. To further exemplify product diversity, the addition of alternative nucleophiles to give isolable products at the end of the reaction was investigated. Using unsubstituted bis-sulfone 33, addition of pyrrolidine gave tertiary amide 56 in high yield and er (75\%, > 99:1 er) on a 3 mmol scale allowing the formation of $1.12 \mathrm{~g}$ of product. Addition of methanol provided ester $\mathbf{5 7}$ in excellent yield and er.

Having demonstrated the scope and limitations of this protocol, it was proposed that the sulfone functional handle in the product could be exploited to carry out further manipulations to access complex, valuable products. Following a procedure developed by Williams and co-workers, ${ }^{[24]}$ initial studies focused on desulfonylation using magnesium turnings in methanol at room temperature (Scheme 4a). Desulfonylation of 2,3-diphenyl substituted amide gave anti-product 59 in good yield (57\%), whilst maintaining stereointegrity (> 95:5 dr, 99:1 er). Desulfonylation of pyrrolidinyl and benzyl-amides containing a single stereogenic centre was also successful, providing amides 60 and 61 in improved yield (63\% and 77\%). Desulfonylation of 4-fluorophenyl amide $\mathbf{5 1}$ and thiophenyl amide $\mathbf{5 0}$ proved amenable to the unmasking conditions, allowing access to single enantiomers of products $\mathbf{6 2}$ and $\mathbf{6 3}$ in moderate yield. Alternatively, the pro-nucleophilic nature of the bis-sulfone moiety could be exploited to allow further functionalization (Scheme 4b). Treatment of $\mathbf{5 6}$ with either methyl vinyl ketone (MVK) or benzyl bromide under basic conditions gave chain extended amides 64 and 65 respectively in good yield whilst maintaining enantiopurity. 
(a) Desulfonylation

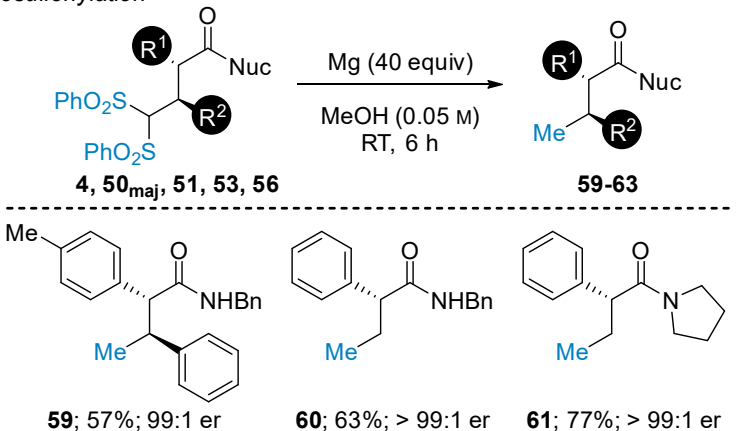

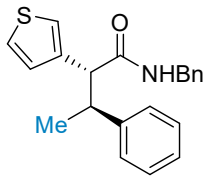

63; $51 \%$; > 99:1 er

(b) Alkylation

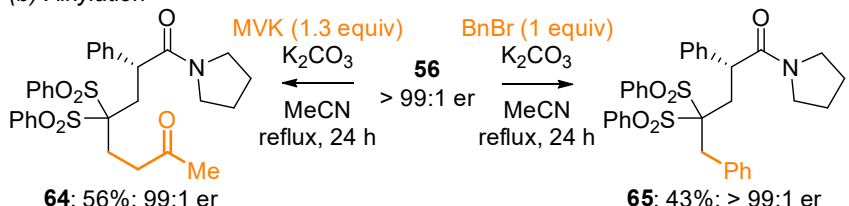

64; $56 \%$; $99: 1$ er

Scheme 4. Product derivatization through (a) desulfonylation and (b) alkylation. (MVK: methyl vinyl ketone).

\section{Mechanistic Studies}

\subsection{Quantitative ${ }^{19} \mathrm{~F}\left\{{ }^{1} \mathrm{H}\right\}$ NMR Reaction Monitoring}

Having demonstrated the reaction scope, further studies sought to provide mechanistic insight into this developed methodology through kinetic analysis. Primary studies set out to identify the catalyst resting state and any potential reaction intermediates, as well as determining the reaction order with respect to each component. Quantitative reaction monitoring was achieved by in situ ${ }^{19} \mathrm{~F}\left\{{ }^{1} \mathrm{H}\right\}$ NMR spectroscopy using ${ }^{19} \mathrm{~F}$-labelled ester $66\left(\delta_{\mathrm{F}}\right.$ -123.36), ${ }^{19} \mathrm{~F}$-labelled electrophile $31\left(\delta_{\mathrm{F}}-107.64\right)$ and ${ }^{19} \mathrm{~F}-\mathrm{BTM}$ $67\left(\delta_{\mathrm{F}}-122.26\right)$ in $\mathrm{CD}_{2} \mathrm{Cl}_{2}[0.1 \mathrm{M}]$ using 1,3-difluorobenzene $\left(\delta_{\mathrm{F}}\right.$ -110.73 ) as an internal standard (Figure 1a). Under these conditions, the reaction time $(3 \mathrm{~h})$ was substantially shorter than the standard conditions $(24 \mathrm{~h}$ ) enabling facile NMR analysis over the course of the reaction (Figure 1b) and giving product 68 in $82 \%$ yield, $88: 12 \mathrm{dr}$ and $>99: 1$ er. $^{[25]}$ During the course of the reaction, both diastereoisomeric reaction products, each containing two distinct ${ }^{19} \mathrm{~F}$-environments, were observed and were distinguishable from the starting components. Monitoring the reaction over time revealed the ${ }^{19} \mathrm{~F}$ chemical shift of ${ }^{19} \mathrm{~F}$-BTM 67 underwent a downfield shift $\left(\delta_{\mathrm{F}}-122.26\right.$ to $\left.\delta_{\mathrm{F}}-121.99 \mathrm{ppm}\right)$ during the reaction, indicative of partial protonation, and hence deactivation, of the catalyst. ${ }^{[26]}$ To account for this observation within the kinetic analysis, ${ }^{19} \mathrm{~F}-\mathrm{BTM} \cdot \mathrm{HCl}$ was synthesized as a standard $\left(\delta_{\mathrm{F}}-115.64 \mathrm{ppm}\right)$, allowing the concentration of free catalyst to be calculated as a function of $\delta_{\mathrm{F}}$ (See SI). ${ }^{[27]}$ These studies are consistent with the dominant catalyst resting state being the free catalyst throughout the reaction protocol. The acyl ammonium salt of the starting ester was synthesized as both the chloride $\left(\delta_{\mathrm{F}}-115.52\right)$ and 2-fluoro-4-nitrophenoxide $\left(\delta_{\mathrm{F}}-111.70\right)$ counterions as potential intermediates (see SI). However, no long-lived intermediates corresponding to $>1 \%$ of the reaction mixture were observed during the reaction. ${ }^{[28]} \mathrm{A}$ similar approach was attempted to form the acyl ammonium of the product (see SI); catalyst 67 was added to product 68 , however no acyl ammonium was observed. ${ }^{[29]}$ Whilst no significant quantities of other intermediates were detected during the analysis of this reaction, an alternative intramolecular catalyst turnover event to form a reactive, short-lived intermediate which is intercepted by the aryloxide to form acyl ammonium product cannot be ruled out. Such mechanistic alternatives could involve cyclisation through the sulfone oxygen, ${ }^{[6]}$ or via a cyclobutanone intermediate. ${ }^{[30]}$

\subsection{Kinetic Analysis}

Having determined the temporal concentration of the reaction components, information concerning their reaction orders was sought. The inventive variable time normalization analysis (VTNA) reported by Burés was employed, which allows facile, rapid elucidation of reaction orders by using temporal concentration data. ${ }^{[31]}$ Kinetic analysis was carried out by performing seven different reactions, each with varying concentrations of ester $66(120-180 \mathrm{mM})$, electrophile 31 (80$120 \mathrm{mM})$ and catalyst ${ }^{19} \mathrm{~F}-67(16-24 \mathrm{mM})$. Visual analysis of the data was achieved by plotting the concentration of product 68 (sum of both diastereoisomers) against a time normalized axis of $\Sigma[66]^{\alpha}[31]^{\beta}[67]^{\gamma} \Delta$ t. Subsequent variation of $\alpha, \beta$ and $\gamma$ was (a)<smiles>O=C(Cc1ccccc1)Oc1ccc([N+](=O)[O-])cc1F</smiles>

66 (120-180 mM), $\delta_{F}-123.36 \bigcirc 31$ (80-120 mM), $\delta_{F}-107.64$
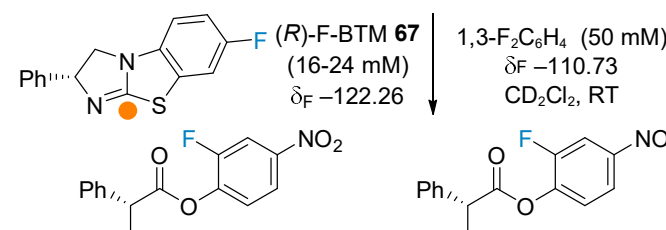<smiles>O=S(=O)(O)c1ccccc1</smiles>

$68_{\mathrm{maj}}, \delta_{\mathrm{F}}-113.88,-123.47$ $82 \% ; 88: 12 \mathrm{dr} ;>99: 1 \mathrm{er}_{\mathrm{ma}}$

(b) Reaction profile

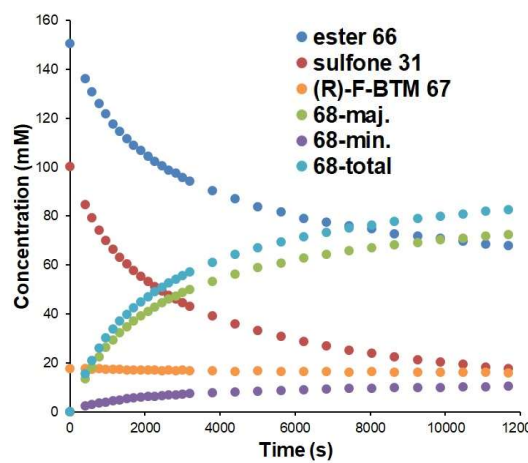

(c) VTNA

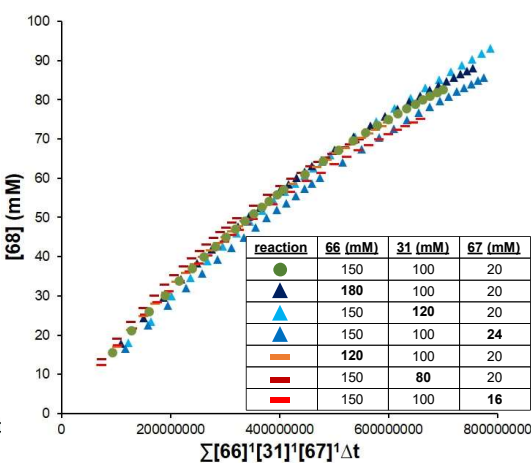

Figure 1. Mechanistic studies: (a) ${ }^{19} \mathrm{~F}\left\{{ }^{1} \mathrm{H}\right\}$ NMR Spectroscopy for reaction mechanism analysis; (b) reaction profile using $150 \mathrm{mM} 6 \mathbf{6}, 100 \mathrm{mM} 31$ and $20 \mathrm{mM} 67$; (c) variable time normalization analysis, $\alpha=1, \beta=1$, and $y=1$. 
carried out to achieve best overlay. Variation of $\alpha, \beta$ and $y$ at integer and half-integer values from 0 to 2 (see $\mathrm{SI}$ ) showed best overlay when each component was set to 1 . This is consistent with the reaction being first order in each of the three components, and indicates with the turnover-limiting step is likely to be either Michael addition or catalyst turnover (Figure 1c). Significantly, this mechanistic information contrasts our previous work regarding enantioselective Michael additionlactonizations that utilized intramolecular catalyst turnover in ammonium enolate catalysis (Scheme 1). ${ }^{[6]}$ In this previous work, the process was found to be zero order in electrophile, with deprotonation of the acyl ammonium ion identified as the turnover-limiting step through a significant primary KIE. This is consistent with two mechanistically distinct scenarios being operative in these reactions.

\subsection{Product Inhibition}

Although reasonable overlay had been achieved, the observed curvature in Figure $1 \mathrm{c}$ indicates an additional variable, which has an effect of reducing the reaction rate over time, remained unaccounted for. As catalyst deactivation through protonation had already been included in the kinetic analysis, the potential for product inhibition was considered. Consistent with this hypothesis, incorporation of the product concentration into the time normalization approach $\Sigma[66]^{1}[31]^{1}[67]^{1}[68]^{\delta} \Delta t$, and arbitrarily setting $\delta=-0.2$ improved the linearity of the plot (see $\mathrm{SI})$. A series of control reactions were therefore untaken and compared to the standard reaction profile (Figure 2). Reactions with $20 \mathrm{~mm}$ product 68 added at the start of the reaction were carried out in triplicate, with the displayed profile an average of these three runs. It is clearly noticeable that the observed rate of vinyl bis-sulfone consumption is reduced in comparison to the standard reaction. Using the VTNA approach to estimate $k_{\mathrm{obs}}$,
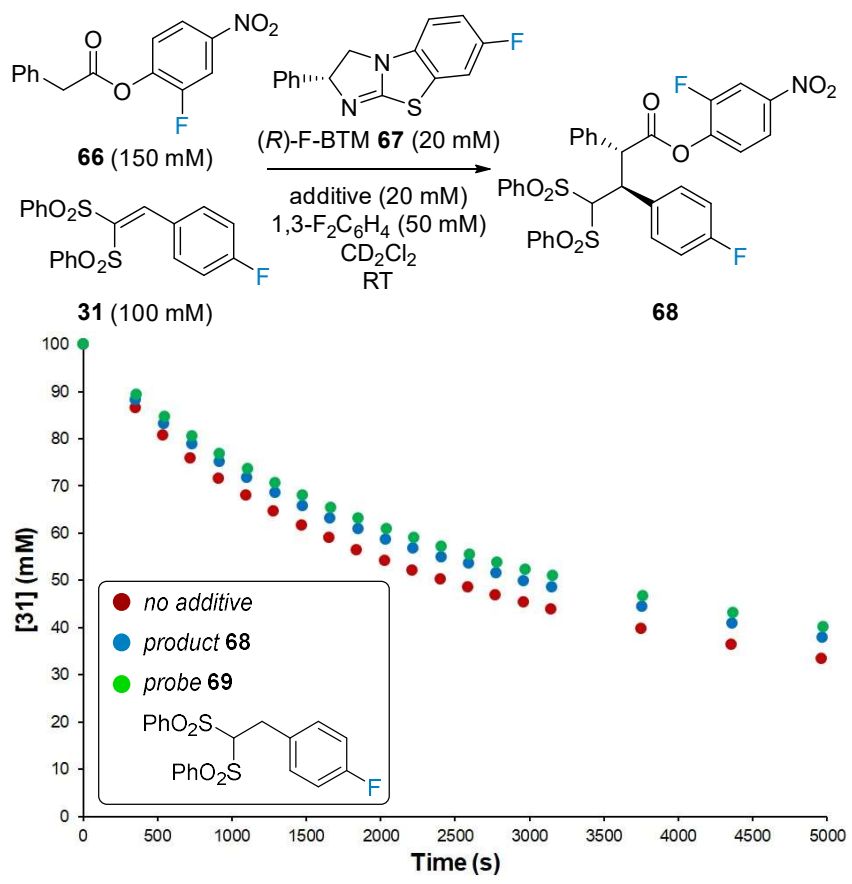

Figure 2. Product inhibition study

the magnitude of $k_{\mathrm{obs}}$ was calculated to be 0.86 the magnitude of $k_{\mathrm{obs}}$ of the standard reaction (see $\mathrm{SI}$ ). It was proposed the cause of the product inhibition could be the acidic proton adjacent to the bis-sulfone functionality. Consistent with this hypothesis, the addition of $20 \mathrm{mM}$ of the saturated bis-sulfone 69 at the start of the reaction resulted in a similar retardation of the reaction rate. Using an identical protocol to that above, the magnitude of $k_{\text {obs }}$ was calculated to be 0.80 the magnitude of $k_{\text {obs }}$ of the standard reaction. Based on these results, it is postulated that the product may inhibit the reaction by protonating either the $\mathrm{C}(1)$ ammonium enolate or aryloxide, thus retarding the rate of catalyst turnover.

\subsection{Inverse Secondary Kinetic Isotope Effect}

To further probe the reaction mechanism the leverage of a secondary kinetic isotope effect was investigated. The change in hybridization of an $\mathrm{sp}^{2}$-hybridized Michael acceptor to an $\mathrm{sp}^{3}$ hybridized product has previously been used to probe the turnover limiting step of Michael addition reactions through the observation of an inverse secondary kinetic isotope effect. ${ }^{[32,33]}$ We sought to generate this information through a direct competition experiment between enantioselective addition of ester 66 to a 50:50 ratio of isotopologues $\mathrm{C}(2)-\mathrm{H} 31\left(\delta_{\mathrm{F}}-107.64\right)$ and $C(2)-D 70\left(\delta_{F}-107.51\right)$ in solution. Monitoring the relative rates of consumption of $\mathrm{C}(2)-\mathrm{H} 31$ and $\mathrm{C}(2)-\mathrm{D} 70$ in triplicate gave a kinetic isotope effect $k_{H} / k_{D}=0.88$ (Scheme 5). For comparison, a similar effect $\left(k_{H} / k_{D}=0.89\right)$ was observed in separate independent parallel kinetic experiments using $\mathrm{C}(2)-\mathrm{H}$ 31 and C(2)-D 70 (see SI). This information is consistent with the Michael addition being kinetically significant in this protocol and contrasts the intramolecular catalyst turnover approach in formal [4+2] cycloadditions, in which acyl ammonium deprotonation was observed to be turnover-limiting. ${ }^{[6]}$

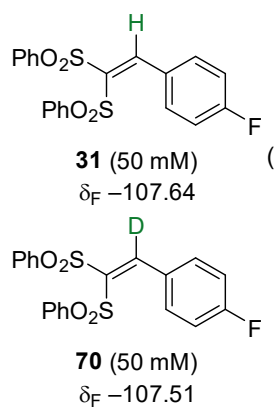

Scheme 5. Inverse secondary kinetic isotope effect.

\subsection{Proposed Mechanism}

Taking all the mechanistic information into account, the following mechanism is proposed (Scheme 6). The catalytic cycle starts by reversible $\mathrm{N}$-acylation of free base BTM catalyst I with ester II to form acyl ammonium ion pair III. Reversible deprotonation of the acyl ammonium by the aryloxide counteranion affords the nucleophilic ammonium enolate IV and releases paranitrophenol. It is proposed that a $1,5-0 . \cdots$ S interaction (characterized as $n_{\circ}$ to $\sigma^{*} \mathrm{C}-\mathrm{S}$ ) ${ }^{[34]}$ lowers the rotational freedom of this intermediate, with the stereodirecting phenyl group forced to 
adopt a pseudo-axial position to minimize 1,2-strain, and hence blocking the Si face of the enolate intermediate. Turnover ratelimiting Michael addition to the electrophile $\mathbf{V}$ on the $R e$ face of the enolate leads to intermediate VI. Protonation by the paranitrophenol released in step two gives acyl ammonium ion-pair VII. Addition of the aryloxide anion forms the product VIII and regenerates catalyst $\mathbf{I}$, which is in equilibrium with the catalytically inactive protonated-BTM IX. Critical to the success of this protocol is the aryloxides ability to act as the leaving group, Brønsted base, Brønsted acid and nucleophile to turnover the catalyst, enabling the reaction to be carried out in the absence of auxiliary base. The observed diastereoselectivity can be rationalized tentatively by a favoured open pre-transition state assembly TS-I where gauche interactions are minimized about the forming $\mathrm{C}-\mathrm{C}$ bond ${ }^{[35]}$ while allowing a potentially favourable $\pi$-cation interaction ${ }^{[36]}$ between the $\beta$-substituent of the bis-sulfone electrophile and the isothiouronium cation (Scheme 6). Interestingly, the relative configuration within the major diastereoisomer obtained using these bis-sulfone electrophiles is opposite to that observed in previous isothiourea catalysis employing intramolecular catalyst turnover processes (Scheme 1) and in the intermolecular addition to iminium ions (Scheme 2c). This difference can presumably be rationalized due to the two highly sterically demanding sulfone groups of this series of electrophile.

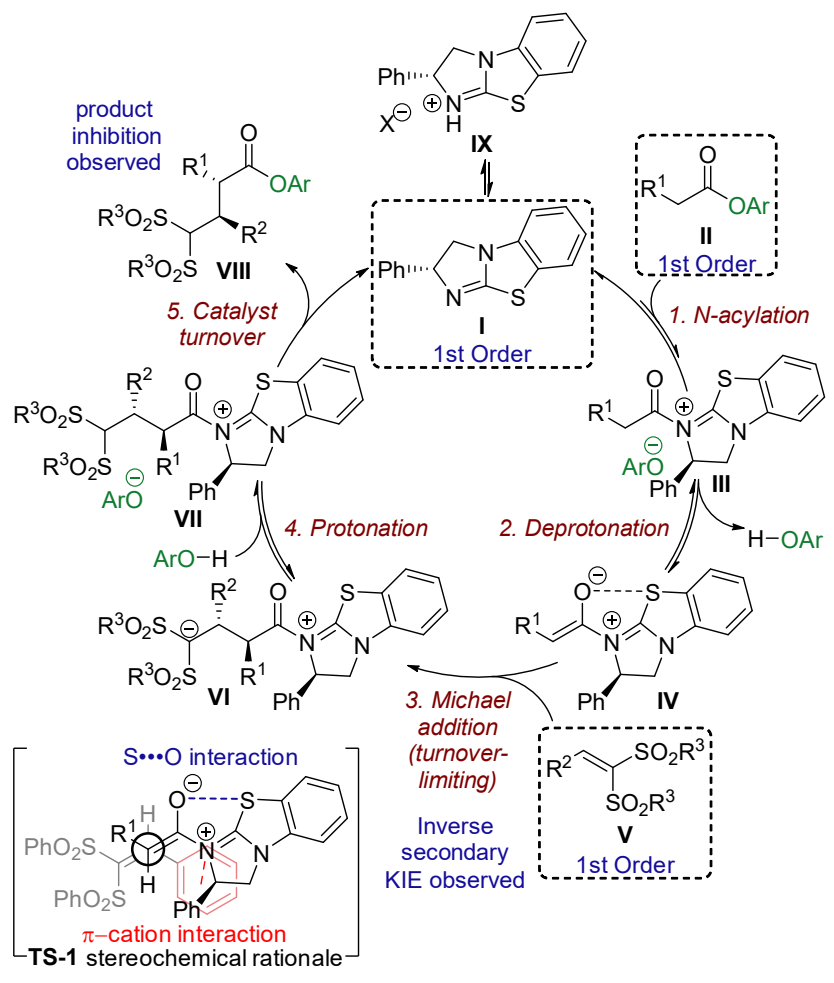

Scheme 6. Proposed Mechanism.

\section{Conclusion}

In conclusion, a base-free and proton neutral enantioselective Michael addition of ester pronucleophiles to vinyl bis-sulfones has been developed. This protocol, which can be carried out in environmentally benign solvents, allows formation of $\alpha$-alkylated products in excellent yield and with excellent diastereo- and enantioselectivity using low catalyst loadings (26 examples, up to $90: 10 \mathrm{dr}$ and $\geq 99: 1 \mathrm{er}$ ). Notably, no auxiliary base is required for this Michael addition process, with the key role of the aryloxide to act firstly as a leaving group, then a Brønsted base, a Brønsted acid and finally a Lewis base to promote catalyst turnover. The functional products can be deprotected upon treatment with $\mathrm{Mg}$ in $\mathrm{MeOH}$ to form $\alpha$-alkylated amides without loss of stereointegrity. Mechanistic investigations using ${ }^{19} \mathrm{~F}\left\{{ }^{1} \mathrm{H}\right\}$ NMR spectroscopy have enabled detailed investigation of the speciation within the reaction, with a variable time normalization analysis and an inverse secondary KIE indicative of Michael addition being the turnover-limiting step. Catalyst protonation, alongside product inhibition were also identified during this analysis. It is hoped that this mechanistic study will aid future reaction design in enantioselective ammonium enolate catalysis, and we are actively exploring these possibilities in our laboratory. ${ }^{[37]}$

\section{Acknowledgements}

We thank the European Research Council under the European Union's Seventh Framework Programme (FP7/2007-2013) ERC grant agreement no. 279850 (A.D.S) and the EPSRC (EP/M508214/1, C.M.) for funding. A.D.S. thanks the Royal Society for a Wolfson Research Merit Award. We also thank the EPSRC UK National Mass Spectrometry Facility at Swansea University. We thank $\mathrm{Dr}$ Siobhan Smith for assistance with manual NMR experiments.

Keywords: isothiourea catalysis • enantioselective Michael addition $\cdot$ base free / proton neutral $\cdot$ mechanistic analysis $\cdot$ VTNA $\bullet$ inverse secondary kinetic isotope effect

[1] a) M. J. Gaunt, C. C. C. Johansson, Chem. Rev. 2007, 107, 5596-5605 b) L. C. Morrill, A. D. Smith, Chem. Soc. Rev. 2014, 43, 6214-6226.

[2] a) G. C. Fu, Acc. Chem. Res. 2000, 33, 412-420; b) S. France, D. J. Guerin, S. J. Miller, T. Lectka, Chem. Rev. 2003, 103, 2985-3012; c) S. E. Denmark, G. L. Beutner, Angew. Chem. 2008, 120, 1584-1663 Angew. Chem. Int. Ed. 2008, 47, 1560-1638; d) J. E. Taylor, S. D. Bull J. M. J. Williams, Chem. Soc. Rev. 2012, 41, 2109-2121; e) J. Merad, J.-M. Pons, O. Chuzel, C. Bressy, Eur. J. Org. Chem. 2016, 5589-5610.

[3] a) H. Wynberg, E. G. J. Staring, J. Am. Chem. Soc. 1982, 104, 166168; b) A. E. Taggi, A. M. Hafez, H. Wack, B. Young, W. J. Drury, III, T. Lectka, J. Am. Chem. Soc. 2000, 122, 7831-7832; c) B. L. Hodous, G. C. Fu, J. Am. Chem. Soc. 2002, 124, 1578-1579; d) J. E. Wilson, G. C. Fu, Angew. Chem. 2004, 116, 6518-6520; Angew. Chem. Int. Ed. 2004, 43, 6358-6360; e) T. Bekele, M. H. Shah, J. Wolfer, C. J. Abraham, A. Weatherwax, T. Lectka, J. Am. Chem. Soc. 2006, 128, 1810-1811; f) X. $\mathrm{Xu}$, K. Wang, S. G. Nelson, J. Am. Chem. Soc. 2007, 129, 1169011691; g) D. H. Paull, A. Weatherwax, T. Lectka, Tetrahedron 2009, 65, 6771-6803.

[4] a) G. S. Cortez, R. L. Tennyson, D. Romo, J. Am. Chem. Soc. 2001, 123, 7945-7946; b) S. H. Oh, G. S. Cortez, D. Romo, J. Org. Chem. 2005, 70, 2835-2838; c) H. Henry-Riyad, C. Lee, V. C. Purohit, D Romo, Org. Lett. 2006, 8, 4363-4366; d) V. C. Purohit, A. S. Matla, D. Romo, J. Am. Chem. Soc. 2008, 130, 10478-10479; e) K. A. Morris, K. M. Arendt, S. H. Oh, D. Romo, Org. Lett. 2010, 12, 3764-3767; f) C. A 
Leverett, V. C. Purohit, D. Romo, Angew. Chem. 2010, 122, 9669 9673; Angew. Chem. Int. Ed. 2010, 49, 9479-9483; g) D. Sikriwal, D. K Dikshit, Tetrahedron 2011, 67, 210-215; h) D. Belmessieri, L. C. Morrill, C. Simal, A. M. Z. Slawin, A. D. Smith, J. Am. Chem. Soc. 2011, 133 2714-2720; i) C. Simal, T. Lebl, , A. M. Z. Slawin, A. D. Smith, Angew. Chem. 2012, 124, 3713-3717; Angew. Chem. Int. Ed. 2012, 51, 3653 3657 ; j) L. C. Morrill, T. Lebl, A. M. Z. Slawin, A. D. Smith, Chem. Sci. 2012, 3, 2088-2093; k) D. Belmessieri, D. B. Cordes, A. M. Z. Slawin, A D. Smith, Org. Lett. 2013, 15, 3472-3475; I) L. C. Morrill, D. G. Stark, J. E. Taylor, S. R. Smith, J. A. Squires, A. C. A. D'Hollander, C. Simal, P. Shapland, T. J. C. O'Riordan, A. D. Smith, Org. Biomol. Chem. 2014 12, 9016-9027; m) P.-P. Yeh, D. S. B. Daniels, C. Fallan, E. Gould, C Simal, J. E. Taylor, A. M. Z. Slawin, A. D. Smith, Org. Biomol. Chem. 2015, 13, 2177-2191; n) L. Hesping, A. Biswas, C. G. Daniliuc, C Mück-Lichtenfeld, A. Studer, Chem. Sci. 2015, 6, 1252-1257; o) J. Izquierdo, M. A. Pericàs, ACS Catal. 2016, 6, 348-356; p) D. G. Stark P. Williamson, E. R. Gayner, S. F. Musolino, R. W. F. Kerr, J. E. Taylor A. M. Z. Slawin, T. J. C. O'Riordan, S. A. Macgregor, A. D. Smith, Org. Biomol. Chem. 2016, 14, 8957-8965; q) R. M. Neyyappadath, D. B Cordes, A. M. Z. Slawin, A. D. Smith, Chem. Commun. 2017, 53, 25552558; r) S. Wang, J. Izquierdo, C. Rodríguez-Escrich, M. A. Pericàs, ACS Catal. 2017, 7, 2780-2785; s) S. Wang, C. Rodríguez-Escrich, M A. Pericàs, Angew. Chem. 2017, 129, 15264-15268; Angew. Chem. Int. Ed. 2017, 56, 15068-15072; t) J. Song, Z.-J. Zhang, L.-Z. Gong, Angew. Chem. 2017, 129, 5296-5300; Angew. Chem. Int. Ed. 2017, 56, 52125216; u) S. Zhang, J. E. Taylor, A. M. Z. Slawin, A. D. Smith, Org. Lett 2018, 20, 5482-5485.

[5] a) J. Song, Z.-J. Zhang, S.-S. Chen, T. Fan, L.-Z. Gong, J. Am. Chem Soc. 2018, 140, 3177-3180; b) C. M. Young, J. E. Taylor, A. D. Smith Org. Biomol. Chem. 2019, 17, 4747-4752; c) L. Hao, X. Chen, S. Chen, K. Jiang, J. Torres, Y. R. Chi, Org. Chem. Front. 2014, 1, 148-150.

[6] L. C. Morrill, J. Douglas, T. Lebl, A. M. Z. Slawin, D. J. Fox, A. D. Smith, Chem. Sci. 2013, 4, 4146-4155.

[7] a) H. Wack, A. E. Taggi, A. M. Hafez, W. J. Drury, III, T. Lectka, J. Am. Chem. Soc. 2001, 123, 1531-1532; b) A. M. Hafez, A. E. Taggi, H Wack, J. Esterbrook, T. Lectka, Org. Lett. 2001, 3, 2049-2051; c) A. E. Taggi, H. Wack, A. M. Hafez, S. France, T. Lectka, Org. Lett. 2002, 4, 627-629; d) S. France, H. Wack, A. E. Taggi, A. M. Hafez, T. R. Wagerle, M. H. Shah, C. L. Dusich, T. Lectka, J. Am. Chem. Soc. 2004 126, 4245-4255; e) D. Bernstein, S. France, J. Wolfer, T. Lectka, Tetrahedron: Asymmetry 2005, 16, 3481-3483.

[8] W. C. Hartley, T. J. C. O'Riordan, A. D. Smith, Synthesis 2017, 49, 3303-3310.

[9] T. H. West, D. S. B. Daniels, A. M. Z. Slawin, A. D. Smith, J. Am. Chem Soc. 2014, 136, 4476-4479.

[10] T. H. West, D. M. Walden, J. E. Taylor, A. C. Brueckner, R. C Johnston, P. H.-Y. Cheong, G. C. Lloyd-Jones, A. D. Smith, J. Am. Chem. Soc. 2017, 139, 4366-4375.

[11] a) K. J. Schwarz, J. L. Amos, J. C. Klein, D. T. Do, T. N. Snaddon, J. Am. Chem. Soc. 2016, 138, 5214-5217; b) J. W. B. Fyfe, O. M. Kabia, C. M. Pearson, T. N. Snaddon, Tetrahedron 2018, 74, 5383-5391; c) K J. Schwarz, C. M. Pearson, G. A. Cintron-Rosado, P. Liu, T. N. Snaddon, Angew. Chem. 2018, 130, 7926-7929; Angew. Chem. Int. Ed. 2018, 57, 7800-7803; d) K. J. Schwarz, C. Yang, J. W. B. Fyfe, T. N Snaddon, Angew. Chem. 2018, 130, 12278-12281; Angew. Chem. Int Ed. 2018, 57, 12102-12105; e) W. R. Scaggs, T. N. Snaddon, Chem. Eur. J. 2018, 24, 14378-14381; f) L. Hutchings-Goetz, C. Yang, T. N Snaddon, ACS Catal. 2018, 8, 10537-10544; g) W. R. Scaggs, T. D. Scaggs, T. N. Snaddon, Org. Biomol. Chem. 2019, 17, 1787-1790.

[12] X. Jiang, J. J. Beiger, J. F. Hartwig, J. Am. Chem. Soc. 2017, 139, $87-$ 90.

[13] J. N. Arokianathar, A. B. Frost, A. M. Z. Slawin, D. Stead, A. D. Smith, ACS Catal. 2018, 8, 1153-1160.

[14] R. K. Henderson, C. Jiménez-González, D. J. C. Constable, S. R. Alston, G. G. A. Inglis, G. Fisher, J. Sherwood, S. P. Binks, A. D. Curzons, Green Chem. 2011, 13, 854-862.
[15] For an extensive study on the ambient reactivity of phenolate anions see a) R. J. Mayer, M. Breugst, N. Hampel, A. R. Ofial, H. Mayr, J. Org Chem. 2019, DOI: 10.1021/acs.joc.9b01485. For a study on the nucleofugality of phenolate anions see b) M. Matić, N. Bebek, B Denegri, O. Kronja, Croat. Chem. Acta 2016, 89, 355-362; For a review on the nucleofugality of leaving groups see c) M. Matić, B. Denegri, N Bebek, S. Jurić, O. Kronja, Croat. Chem. Acta 2017, 90, 571-581.

[16] S. Espinosa, E. Bosch, M. Rosés, J. Chromatogr. A 2002, 964, 55-66.

[17] J. Han, F.-M. Tao, J. Phys. Chem. A 2006, 110, 257-263.

[18] 2,4,6-Trichlorophenol esters have been previously shown to acylate isothiourea catalysts. For examples see reference 5 , and a) A. Matviitsuk, J. E. Taylor, D. B. Cordes, A. M. Z. Slawin, A. D. Smith, Chem. Eur. J. 2016, 22, 17748-17757; b) M. D. Greenhalgh, S. Qu, A. M. Z. Slawin, A. D. Smith, Chem. Sci. 2018, 9, 4909-4918.

[19] It is envisaged the use of green solvents in combination with higher catalyst loadings could be applied to achieve similarly high yields.

[20] CCDC $1939040\left(\mathbf{4}_{\mathrm{maj}}\right)$ contains the supplementary crystallographic data for this paper. These data can be obtained free of charge from The Cambridge Crystallographic Data Centre.

[21] Epimerization of the post-Michael addition acyl ammonium ion cannot be ruled out.

[22] CCDC $1939041\left(\mathbf{5 0}_{\mathrm{min}}\right)$ contains the supplementary crystallographic data for this paper. These data can be obtained free of charge from The Cambridge Crystallographic Data Centre.

[23] This current limitation is proposed to be due to the lower acidity of the proton in the a-position.

[24] L. Acemoglu, J. M. J. Williams, J. Mol. Cat. A: Chemical 2003, 196, 311.

[25] The reaction time is considerably shorter ( $3 \mathrm{~h}$ ) because $20 \mathrm{~mol} \%$ catalyst was used compared to $5 \mathrm{~mol} \%$ under the optimized conditions (24 h).

[26] It is proposed that slow partial hydrolysis of ester 66 to phenylacetic acid and 2-fluoro-4-nitrophenol during the reaction could be the source of catalyst protonation. Consistent with this hypothesis, a small quantity of 2-fluoro-4-nitrophenol was observed to form over the reaction course $(<5 \%)$.

[27] T. Rodima, V. Mäemets, I. Koppel, J. Chem. Soc., Perkin Trans. 12000 , 2637-2644.

[28] Two small, unknown peaks were detected: $0.24-0.38 \mathrm{~mm}$ at -111.36 ppm and $0.16-0.84 \mathrm{~mm}$ at $112.14 \mathrm{ppm}$. Both could not be identified as any reaction intermediates.

[29] This suggests that the catalyst turnover step is irreversible, an observation found in previous work concerning the 2,3-rearrangement of ammonium ylides. See reference 11 .

[30] Cyclobutanes have been observed as key intermediates in secondary amine-catalyzed Michael addition reactions; J. Burés, A. Armstrong, D. G. Blackmond, Acc. Chem. Res. 2016, 49, 214-222.

[31] a) J. Burés, Angew. Chem. 2016, 128, 16318-16321; Angew. Chem. Int. Ed. 2016, 55, 16084-16087; b) C. D.-T. Nielsen, J. Burés, Chem. Sci. 2019, 10, 348-353

[32] a) E. V. Anslyn, D. A. Dougherty, Modern Physical Organic Chemistry, University Science Books, Sausalito, California, 2005, pp. 428-430. For a discussion on the interpretation of deuterium kinetic isotope effects see b) E. M. Simmons, J. F. Hartwig, Angew. Chem. 2012, 124, 31203126; Angew. Chem. Int. Ed. 2012, 51, 3066-3072.

[33] Selected examples of observed inverse secondary kinetic isotope effect in Michael addition reactions: a) S. I. Lee, B. C. Kang, G.-S. Hwang, D H. Ryu, Org. Lett. 2013, 15, 1428-1431; b) C. M. Young, D. G. Stark, T. H. West, J. E. Taylor, A. D. Smith, Angew. Chem. 2016, 128, 1460614611; Angew. Chem. Int. Ed. 2016, 55, 14394-14399.

[34] For discussions of $\mathrm{S} \cdots \mathrm{O}$ interactions in isothiourea catalysis: a) $\mathrm{V}$. B. Birman, X. Li, Z. Han, Org. Lett. 2007, 9, 37-40; b) P. Liu, X. Yang, V. B. Birman, K. N. Houk, Org. Lett. 2012, 14, 3288-3291; c) M. E. Abbasov, B. M. Hudson, D. J. Tantillo, D. Romo, J. Am. Chem. Soc. 2014, 136 4492-4495; d) E. R. T. Robinson, D. M. Walden, C. Fallan, M. D. Greenhalgh, P. H.-Y. Cheong, A. D. Smith, Chem. Sci. 2016, 7, 6919- 
6927; e) M. D. Greenhalgh, S. M. Smith, D. M. Walden, J. E. Taylor, Z. Brice, E. R. T. Robinson, C. Fallan, D. B. Cordes, A. M. Z. Slawin, H. C. Richardson, M. A. Grove, P. H.-Y. Cheong, A. D. Smith, Angew. Chem. 2018, 130, 3254-3260; Angew. Chem. Int. Ed. 2018, 57, 3200-3206. for use of $\mathrm{S} \cdots \mathrm{O}$ interaction in asymmetric synthesis: f) $\mathrm{Y}$. Nagao, $\mathrm{S}$ Miyamoto, M. Miyamoto, H. Takeshige, K. Hayashi, S. Sano, M. Shiro K. Yamaguchi, Y. Sei, J. Am. Chem. Soc. 2006, 128, 9722-9729; for examples of S $\cdots O$ interactions in medicinal chemistry: g) B. R. Beno, K.-S. Yeung, M. D. Bartberger, L. D. Pennington, N. A. Meanwell, J. Med. Chem. 2015, 58, 4383-4438; for a discussion on the origin of chalcogen-bonding interactions: h) D. J. Pascoe, K. B. Ling, S. L. Cockroft, J. Am. Chem. Soc. 2017, 139, 15160-15167.

[35] M. A. Walker, C. H. Heathcock, J. Org. Chem. 1991, 56, 5747-5750.

[36] Review on nitrogen cation- $\pi$ interactions in asymmetric organocatalysis: a) S. Yamada, J. S. Fossey, Org. Biomol. Chem. 2011, 9, 7275-7281; Review on cation- $\pi$ interactions in organic synthesis: b) S. Yamada, Chem. Rev. 2018, 118, 11353-11432.

[37] The research data underpinning this publication can be found at DOI: https://doi.org/10.17630/0dac65b6-0b88-4ab7-9398-d62f5c96e8fb. 
Entry for the Table of Contents (Please choose one layout)

Layout 1:

\section{RESEARCH ARTICLE}

The base-free functionalization of aryl esters to form $\alpha$-alkylated ester products in excellent enantioselectivity (>20 examples, all $\geq 99: 1 \mathrm{er}$ ) is developed using isothiourea catalysis. Key is the multifunctional role of the aryloxide, which operates as a leaving group, Brønsted base, Brønsted acid and Lewis base within the catalytic cycle. Mechanistic studies, including variable time normalization analysis and a kinetic isotope effect, were used to probe the reaction mechanism.

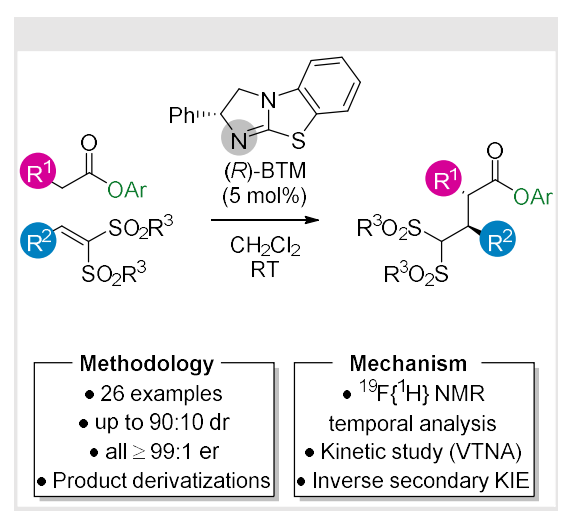

Calum McLaughlin, Alexandra M. Z. Slawin and Andrew D. Smith*

Page No. - Page No.

Base-free Enantioselective C(1)Ammonium Enolate Catalysis Exploiting Aryloxides: A Synthetic and Mechanistic Study 